\title{
AVALIAÇÃO DAS CAUSAS DA OXIDAÇÃO EM BOBINAS LAMINADAS A QUENTE NA ARCELORMITTAL TUBARÃO*
}

\author{
Robson Ferreira Vargas ${ }^{1}$ \\ Uarlem Jose de Farias ${ }^{2}$ \\ Vinicius dos Reis Carvalho ${ }^{3}$ \\ Fabio Schusterschitz da Silva Araújo ${ }^{4}$ \\ Valcir Riberio da Silva ${ }^{5}$
}

\section{Resumo}

No início de Março/2015 começaram a ser notados eventos de oxidação em bobinas armazenadas no pátio de expedição, e naquela época o fenômeno foi creditado às chuvas. Entretanto, passado o período chuvoso, ainda foram notados eventos de oxidação, que ocorriam também em produtos destinados à exportação. Isto mostrou que havia outra causa atuando no problema, e que era necessário descobri-la e tomar ações para sanar o problema. O produto final é a coroação do esforço produtivo anterior à sua obtenção, e leva consigo o nome do fabricante para onde for enviado. Por isto ele não pode ter falhas. A ArcelorMittal Tubarão montou um grupo de trabalho, que atuou em várias frentes, incluindo o condicionamento químico do sistema de resfriamento direto da laminação. Este grupo de trabalho obteve êxito na tarefa e as conclusões obtidas estão mostradas aqui.

Palavras-chave: Causa; Êxito; Condicionamento químico.

\section{EVALUATION OF CAUSES OF THE OXIDATION IN HOT ROLLED COIL IN ARCELORMITTAL TUBARÃO}

\begin{abstract}
In early March / 2015 began to be noticed oxidation events in coils stored in the shipping yard, and at that time the phenomenon has been credited to the rains. However, after the rainy season, they were still noticed oxidation events, which also occurred in products for export. This showed that there was another cause acting on the problem, and that it was necessary to find it and take action to remedy the problem. The final product is the culmination of the previous productive effort to obtain it, and carries the manufacturer's name where is sent. So he cannot have failures. The ArcelorMittal Tubarão has created working group, which acted on several fronts, including the chemical conditioning of direct cooling system of hot strip mill. This working group was successful in the task and the conclusions reached are shown here.
\end{abstract}

Keywords: Causes; Success; Chemical conditioning.

1 Membro da ABM, Engenheiro Materiais e Metalurgia, Especialista da Área de Operação de Laminação de Tiras a Quente da ArcelorMittal Tubarão, Serra, ES.

2 Engenheiro de Produção Pleno, Especialista da Área de assistência técnica da ArcelorMittal Tubarão, Serra, ES.

3 Engenheiro Pós Graduado em Enga Metalúrgica e Materiais, Gerente Regional da NALCO Water An ECOLAB Company.

4 Membro da ABM, Engenheiro Químico, Consultor Técnico da NALCO Water An ECOLAB Company.

5 Engenheiro de Produção, Supervisor de operações da NALCO Water An ECOLAB Company 


\section{INTRODUÇÃO}

A ArcelorMittal Tubarão é uma Usina Siderúrgica Integrada a carvão mineral, localizada na região da Grande Vitória, próxima ao mar. Sua capacidade produtiva é de 7,5 milhões de toneladas por ano de aço líquido. Abastecendo três lingotamentos contínuos de placas e um laminador de tiras a quente de 4.000.000t de bobinas por ano.

A ArcelorMittal Tubarão abastece o mercado nacional e internacional com bobinas a quente. Os laminados a frio são produzidos na ArcelorMittal Vega, em São Francisco do Sul.

A laminação a quente é o processo de conformação mecânica das placas geradas no lingotamento contínuo em bobinas, que no caso da ArcelorMittal Tubarão constitui o produto final. As propriedades mecânicas e de forma também são adquiridas e controladas durante todo o processo de laminação a quente. É um processo com um grande CAPEX.

A ênfase da qualidade do material produzido é requisito chave para o processo. $O$ produto deve ser enviado ao cliente conforme os requisitos que foram acordados na compra, e qualquer divergência pode causar danos à imagem do produtor da bobina. Garantindo a qualidade do que se está entregando também favorece a obtenção de produtos de melhor qualidade nas operações subsequentes.

Para a obtenção de material dentro da especificação é necessário que a operação e a manutenção do laminador estejam sendo feitas de acordo com os padrões estabelecidos. Um dos agentes neste processo é a água, que tem papel muito importante em todo o processo, e para que uma bobina seja produzida, são utilizadas grandes quantidades de água nas várias etapas do processo: descarepação, resfriamento dos fornos de reaquecimento e resfriamento do laminador e resfriamento da tira no "Laminar Flow".

Ao final do ano de 2014 e início do ano de 2015 a crise hídrica fez com que a redução do consumo de água fosse a ordem do dia, contrastando com as necessidades do processo de laminação. Com a redução de consumo, a água ficou mais agressiva devido ao aumento da concentração de sais dissolvidos, tais como o cloreto.

O aparecimento de oxidação nas bobinas estocadas no pátio, a partir de maio de 2015, período próximo à tomada de ações para a redução do consumo de água, trouxe a suspeita de que a água seria a causa desta oxidação.

Este trabalho mostra as ações tomadas para a real determinação da causa da oxidação e também as ações tomadas para mitigar o problema.

\section{HISTÓRICO DO PROBLEMA E AÇOES TOMADAS}

Desde o início de operação da laminação em Setembro/2001até o ano de 2015, não havia sido levantada a Relação Causa / Efeito da qualidade de água e da oxidação das bobinas, apesar deste fenômeno sempre ter ocorrido. Porém devido às novas condições de qualidade de água de resfriamento devido ao aumento de ciclos dos sistemas de resfriamento que servem ao laminador, a AMT resolveu estudar esta hipótese. 
Após solicitação da Assistência Técnica ao Cliente da AMT, foi montado um grupo de estudo composto por especialistas da AMT e da NALCO Water.

Inicialmente, sob o ponto de vista de tratamento de águas, observou-se que o teor de cloretos tinha subido significativamente:

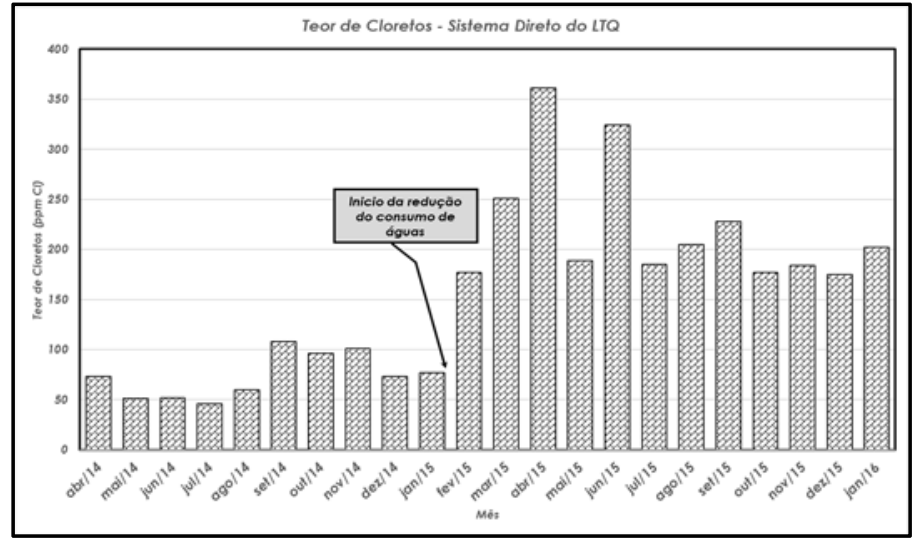

Figura 1. Evolução do Teor de Cloretos no Sistema de Resfriamento Direto da Laminação

Com base nestes dados, iniciaram-se estudos para o uso de biocida oxidante a base de bromo para redução do teor de cloretos. Esta opção não foi estudada antes porque as taxas de corrosão do sistema estavam enquadradas, menores que 5 MPY.

Em visita à área de estocagem foram feitas raspagens em algumas bobinas oxidadas para avaliação da composição química da camada.

Foram retiradas também amostras das tiras estocadas para análise metalográfica nos laboratórios da Nalco em Naperville - Estados Unidos, especialistas neste tipo de análise com enfoque em tratamento de águas.

\section{RESULTADOS E DISCUSSÃO}

\subsection{Analises Químicas}

A tabela 1 a seguir mostra o resultado das análises químicas realizadas nas bobinas:

Tabela 1: Resultado das Análises Químicas Realizadas no Material Raspado de Bobinas Oxidadas

\begin{tabular}{|c|c|c|c|}
\hline Item & Unidade & $\begin{array}{c}\text { Teor Amostra I } \\
\text { (\%) }\end{array}$ & $\begin{array}{c}\text { Teor Amostra II } \\
\text { (\%) }\end{array}$ \\
\hline Perda a $800^{\circ} \mathrm{C}$ & $\mathrm{CO}_{3}$ & 10,4 & 7,5 \\
\hline $\begin{array}{c}\text { Insolúveis em } \\
\mathrm{HCl} / \mathrm{HNO}_{3}\end{array}$ & - & 8,5 & 4,2 \\
\hline Cálcio & $\mathrm{CaO}$ & 2,1 & 0,3 \\
\hline Ferro & $\mathrm{Fe}_{2} \mathrm{O}_{3}$ & 76,2 & 78,8 \\
\hline Fosfato & $\mathrm{P}_{2} \mathrm{O}_{5}$ & 0,5 & 0,4 \\
\hline Sódio & $\mathrm{Na}_{2} \mathrm{O}$ & 1,7 & 0,8 \\
\hline Cloretos & $\mathrm{Cl}$ & 0,6 & 0,9 \\
\hline Outros & - & 0,6 & 8 \\
\hline
\end{tabular}

A perda a $800^{\circ} \mathrm{C}$ inclui carbonatos, compostos orgânicos como óleos e graxas, decomposição de alguns cloretos como $\circ \mathrm{FeCl}_{3}$, alguns compostos de enxofre e água de cristalização 
O elevado teor de ferro na amostra já era esperado, uma vez que o material analisado foi proveniente de bobinas. O baixo teor de fosfato, cloretos e sódio nos depósitos indicam que a participação da água nestes é pequena.

\subsection{Análises Metalográficas}

As amostras retiradas de duas bobinas foram enviadas para o Laboratório Metalográfico da Nalco em Naperville. A figura 2 mostra a face da tira exposta à atmosfera:

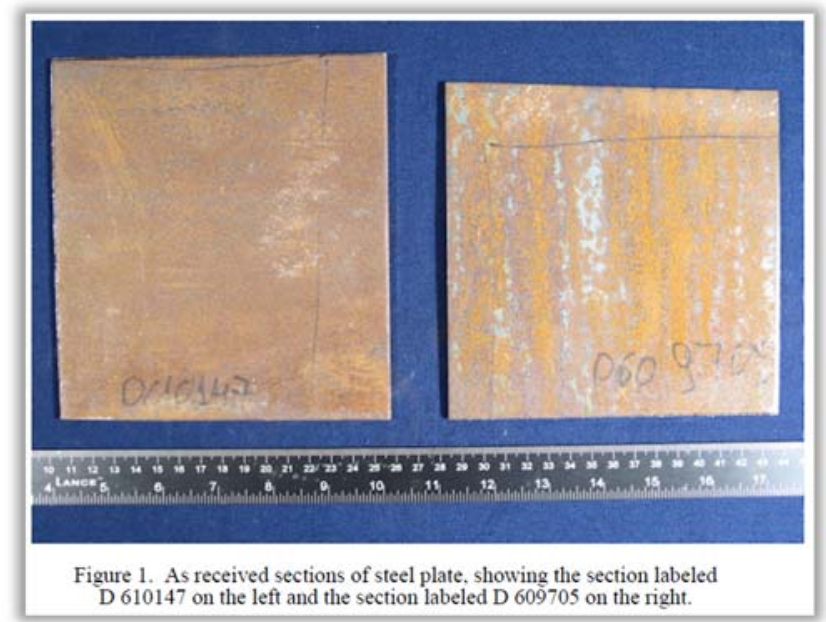

Figura 2. Amostra da Face da Bobina Exposta à Atmosfera

Observa-se a oxidação que cobre vitualmente toda a área da amostra.

A figura 3 mostra a outra face da tira, a face interna, com mínimo contato com a atmosfera:

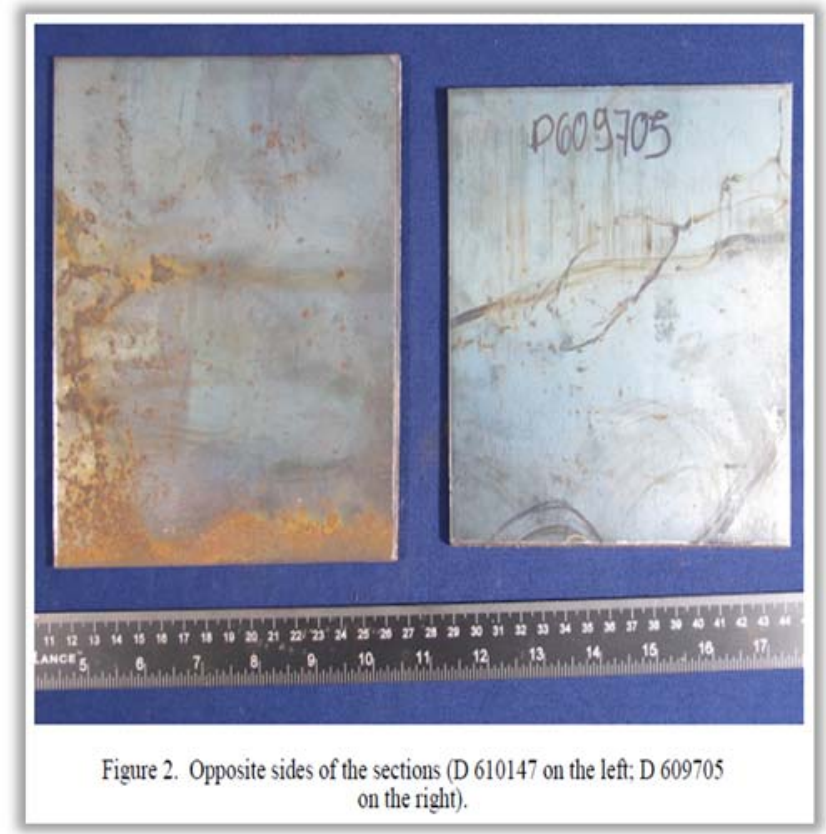

Figura 3. Amostra da Face Interna da Bobina

Nesta face estão presentes apenas a "Mill Scale", sem corrosão significativa. Esta diferença significativa entre as duas faces é um forte indicativo de que a qualidade 
da água de recirculação, pois neste caso as duas faces deveriam apresentar corrosão significativa.

Análise de Microscopia Eletrônica de Varredura - MEV em uma das peças, mostrou presença de ferro (96\%), silício, manganês, cálcio e alumínio, (1\% cada) e traços de enxofre, cloretos e magnésio.

A análise metalográfica mostrou que a causa da corrosão nas bobinas foi corrosão atmosférica, e não corrosão causada pela água de resfriamento.

\subsection{Comentários Sobre A Oxidação}

A carepa de laminação é formada devido à oxidação do aço a altas temperaturas e depende da temperatura alcançada, tempo de exposição e potencial de oxidação durante o processo. Esta camada de carepa de laminação pode fornecer alguma proteção contra corrosão atmosférica. Carepas mais finas são menos protetivas que as mais espessas.

Estas camadas são frágeis e podem se fragmentar sob esforços de flexão ou abrasão.

Muitos fatores podem afetar o aparecimento de corrosão atmosférica e a capacidade de proteção da camada de carepa. A corrosão atmosférica irá ocorrer quando uma superfície de aço sem proteção é exposto à água contendo oxigênio.

Ânions agressivos, tais como o cloreto e sulfato pode acelerar o ataque. Flutuações no clima podem influenciar a corrosão atmosférica.

A Análise Metalográfica mostrou que é improvável que uma pequena alteração na concentração de cloreto da água de refrigeração tivesse tido um impacto significativo sobre a corrosão atmosférica. Todos os depósitos de água de resfriamento teriam sido removidos superfície pela chuva.

\section{CONCLUSÃO}

O trabalho conjunto entre a AMT e a Nalco permitiu determinar que a causa da oxidação das bobinas não é a água de resfriamento. Com a retirada da água da equação, foi possível focar em outros pontos de causa do problema e otimizar a sua mitigação e/ou solução.

Este é um exemplo de um trabalho integrado fornecedor/cliente que obteve resultados positivos e que indicou um caminho a ser seguido, diferente do inicialmente esperado.

As principais conclusões do estudo foram:

- $\quad$ A água de resfriamento não é a causa da oxidação das bobinas:

- Não foram encontrados íons agressivos tanto nas amostras raspadas das bobinas quanto nas amostras enviadas para análise metalográfica;

- Houve corrosão apenas na face $A$ da tira, que estava mais exposta à atmosfera. Na face B, o processo foi muito menor. Veja figuras 1 e 2.

- $\quad$ E importante avaliar com cuidado as causas das não conformidades em sistemas de resfriamento, pois estas não conformidades dificilmente serão causadas apenas pela água;

- O trabalho em conjunto ArcelorMittal e Nalco foi fundamental para determinar as causas da oxidação. 